\title{
Understanding the Latrobe Valley Regional Rehabilitation Strategy and why it is essential
}

\author{
A Feigl State Government of Victoria, Australia \\ B Davis State Government of Victoria, Australia \\ M Pratt State Government of Victoria, Australia \\ A Kirwan State Government of Victoria, Australia \\ B Millsom State Government of Victoria, Australia \\ M Mozina State Government of Victoria, Australia \\ E Rampal State Government of Victoria, Australia
}

\begin{abstract}
The Latrobe Valley Regional Rehabilitation Strategy (LVRRS) seeks to set a safe, stable and sustainable landform for the Latrobe Valley's three coal mine voids and surrounding areas. The strategy is currently under preparation, involving extensive geotechnical, groundwater and surface water studies, the assessment of potential regional impacts on the environment, and the consideration of future land use options. When completed by June 2020, the strategy will provide the Victorian Government and the community with the information required to understand the potential regional impacts of filling (either partially or fully) the mine voids with water to create pit lakes. Engagement with the community, the mine owners and other key stakeholders is an important element of the preparation of the LVRRS.
\end{abstract}

Keywords: mine rehabilitation strategy, mine rehabilitation planning, mine closure planning, Latrobe Valley brown coal mines, pit lakes, mine rehabilitation assessment approach, mining communities in transition

\section{Introduction}

The Latrobe Valley Regional Rehabilitation Strategy (LVRRS) is part of the Victorian Government's response to the findings of the Hazelwood Mine Fire Inquiry (HMFI), which found significant uncertainties and gaps in knowledge surrounding the closure and rehabilitation of the Latrobe Valley's three brown coal mines. Specifically, the Hazelwood Mine Fire Board of Inquiry (2016) found that, with the current knowledge available, some form of pit lake was the most viable rehabilitation option for the coal mine voids, but that there remain many unanswered questions concerning the feasibility of pit lakes.

The LVRRS is addressing some of these knowledge gaps through a series of technical studies, with a final strategy to be completed by June 2020 (Department of Jobs, Precinct and Regions [DJPR] 2018). This paper provides a summary of the approach and method to be applied in preparing the LVRRS.

\section{$1.1 \quad$ Background}

In 2014, a fire occurred at the Hazelwood coal mine that burnt for 45 days. The fire had a significant impact on the nearby community of Morwell and raised serious questions about health effects, the emergency response and the long-term safety of the Latrobe Valley's three brown coal mines.

The Victorian Government implemented a two-part independent inquiry to thoroughly investigate the cause and effects of the mine fire, to consider improvements to the health of the Latrobe Valley community, and to examine the options for rehabilitation of the coal mines once they close. 
In response to the HMFI findings, the State of Victoria released a detailed Hazelwood Mine Fire Inquiry: Victorian Government Implementation Plan (Implementation Plan) (2016) that included a commitment to develop a regional rehabilitation strategy for the Latrobe Valley's three coal mines (the LVRRS). In accordance with the Implementation Plan, the strategy is being developed in consultation with mine owners, relevant water authorities, key stakeholders and the community. The final LVRRS is to be delivered by June 2020 .

The LVRRS is intended to address key knowledge gaps relating to mine rehabilitation as identified by the inquiry. The Victorian Government is responsible for delivering the LVRRS, led by the DJPR in partnership with the Department of Environment, Land, Water and Planning (DELWP).

\subsection{Scope and implementation}

The HMFI: Victorian Government Implementation Plan (2016) outlines the actions to be undertaken to prepare the LVRRS.

The Implementation Plan sets out that DJPR and DELWP, in collaboration with the operators of the Latrobe Valley coal mines and the community, and with input from technical experts, are to undertake the following actions:

- Investigations to address knowledge gaps relating to mine rehabilitation, such as geotechnical stability, hydrogeological risks and water availability.

- Working with the community and the operators of the Latrobe Valley coal mines to understand the findings of these investigations.

- Developing a regional rehabilitation strategy to guide regional level planning for mining operations, rehabilitation, mine closure and post-closure, taking account of the interconnectivity between the three mine voids.

Specifically, the LVRRS investigates the feasibility of full pit lake and partial pit lake rehabilitation options for the Latrobe Valley coal mines, which were found by the inquiry to be 'currently the most viable rehabilitation option, although considerable further investigation is required, as new knowledge could result in an alternative preferred option' (Hazelwood Mine Fire Board of Inquiry 2016, p. 114).

The Implementation Plan divides the delivery of the LVRRS into five stages:

- Stage 1: Project initiation (planning, stakeholder engagement, project team and governance establishment).

- Stage 2: Existing conditions review (data availability, baseline conditions, knowledge gaps).

- Stage 3: Modelling and analysis (prediction of effects, assessment of impacts).

- Stage 4: Integration of findings (cumulative impact and feasibility assessment).

- Stage 5: Ongoing review and adaptation ('living' document phase).

As part of project initiation (Stage 1), a detailed project plan to guide preparation of the LVRRS was developed in consultation with a number of key stakeholders and independent, external experts. The project plan covers investigations contributing to Stages 2, 3 and 4 of the Implementation Plan. The methodology for these investigations draws on expert advice and includes modelling and assessment of several pit lake-based rehabilitation scenarios, building on existing data and current field programs.

In summary, the objective of the LVRRS technical investigation program is to determine if the pit lakes option can deliver a safe, stable and sustainable rehabilitation solution for the Latrobe Valley. The investigations consider the context of limited water availability, a sensitive downstream environment, climate change, aboriginal and non-aboriginal heritage values, and strong community interest in achieving a final landform that can support beneficial land uses. 
The LVRRS also encompasses a land use planning study (see Section 2.5) that is not linked directly with the Implementation Plan.

\subsection{Spatial scale}

The technical studies contributing to the LVRRS encompass the spatial extent relevant to each study objective. This variously encompasses spatial scales from the mine pits, to the inter-mine area, catchment and broader ecosystem. The regional setting for the LVRRS is shown in the Appendix.

\subsection{Temporal scale}

In order to develop a rehabilitation strategy that is sustainable over the long-term in the context of potential climate change, long-term climate variability and future economic and urban development in the region, the LVRRS assesses the potential effects of regional rehabilitation scenarios over a time frame that extends several hundred years. Within this time frame, there are particular time scales or periods that are being considered in detail for each mine, as follows:

- The period from the cessation of mining operations until the final pit lake fill level is reached.

- The initial period (e.g. 10-20 years) after the final pit lake level has been achieved, in which the pit lake may be connected to external water courses and/or management and treatment of water quality may occur.

- The medium-term period (e.g. up to 100 years) after the final pit lake level has been achieved, over which broader impacts of rehabilitation will manifest.

- The long-term period (e.g. beyond 100 years) after the final pit lake level has been achieved, over which the sustainability of the pit lakes may be affected by longer-term climate variability.

\subsection{Closure of Hazelwood coal mine}

The Hazelwood Power Station and coal mine ceased operation on 31 March 2017, and is expected to submit a rehabilitation and closure plan for the mine within 3-5 years of this date. The LVRRS will be prepared by June 2020 and will support a regional, integrated approach to mine rehabilitation planning across all three Latrobe Valley mines. In the period to June 2020, and where possible, the LVRRS will provide interim outputs to support planning for rehabilitation of the Hazelwood coal mine.

\section{Study program}

\subsection{General approach}

The overall objective of the LVRRS is to complete a comparative assessment of the long-term advantages, disadvantages, risks and opportunities associated with various pit lake landforms based on the findings of technical studies and an assessment of cumulative impacts (DJPR 2018).

The final LVRRS report will set out broad parameters for rehabilitation of the three mines (for example, it may state minimum and maximum fill levels for each mine). The LVRRS report to be delivered in 2020 is therefore not intended to propose a single 'master plan'.

The LVRRS considers the mines individually and collectively (cumulatively) in the context of potential impacts (both positive and negative) on the environment, aboriginal and non-aboriginal cultural heritage values, infrastructure and land uses in the Latrobe Valley. The LVRRS gives particular focus to water and land stability issues, noting that the primary objective of rehabilitation is to achieve a safe and stable landform for the closed mine voids.

The biophysical feasibility assessment incorporates an assessment of cumulative impacts, defined as the collective effects of activities and pressures on the environment (e.g. rivers, lakes, flora, fauna), major 
infrastructure (e.g. roads, residential property) and other land uses (e.g. agricultural), both direct and indirect, including present and reasonably foreseeable future pressures.

In parallel with the biophysical assessment, the potential social and economic impacts and opportunities of land uses resulting from or supported by the rehabilitation scenarios are being assessed.

The LVRRS study program consists of geotechnical, water and environmental, and land use planning study streams, and integrated cumulative impact and biophysical feasibility assessments leading to a final report (Figure 1). The components of the study program are summarised in the following sections.

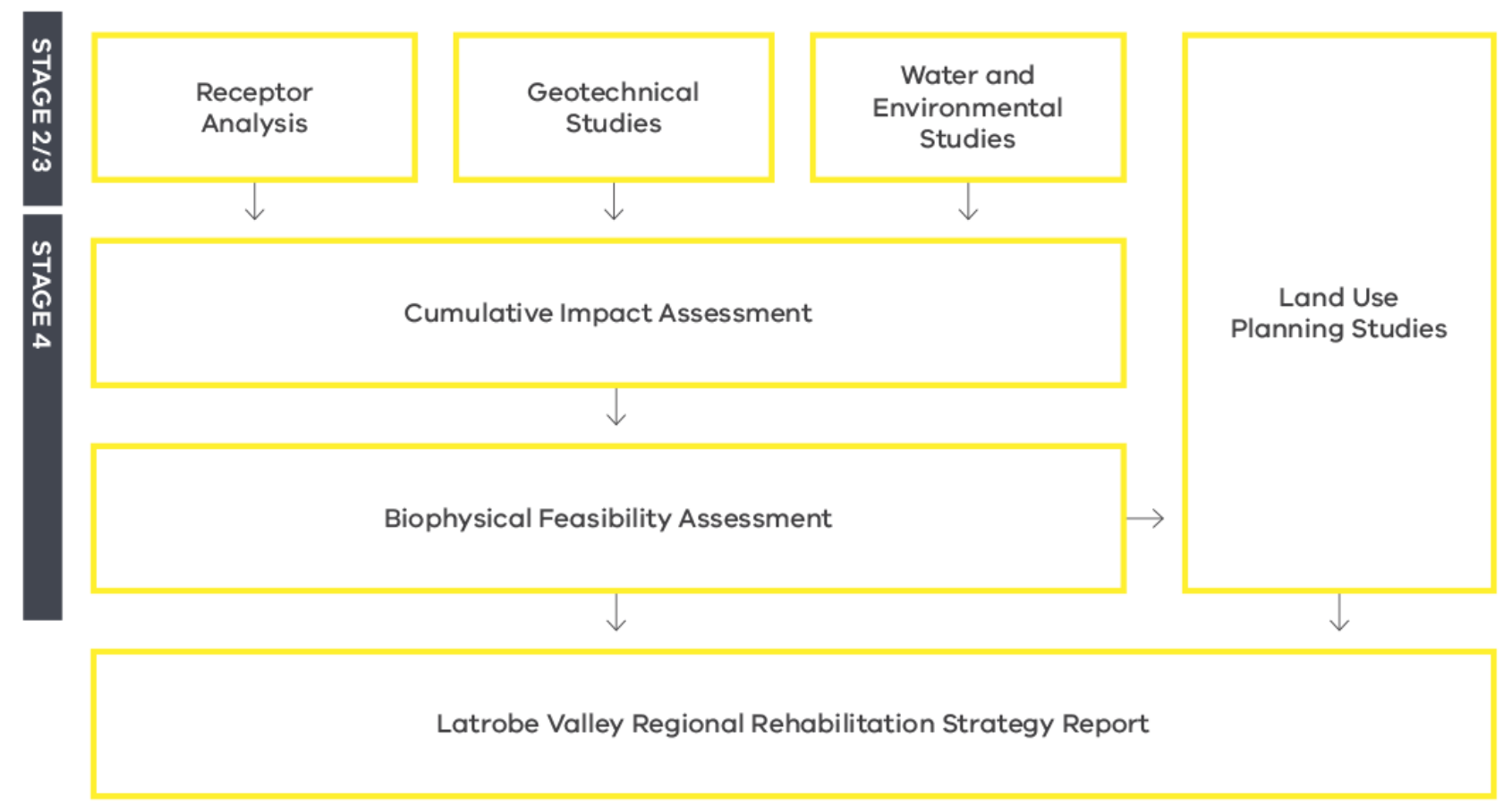

Figure 1 LVRRS study program overview

\section{$2.2 \quad$ Receptor analysis}

The receptor analysis study is not directly linked to the Implementation Plan but represents foundational research that enables all other studies comprising the LVRRS.

Understanding and prioritising the assets, processes and values that could be impacted by mine closure and rehabilitation activities, collectively referred to as 'receptors', is a fundamental premise for the assessment of cumulative impacts (as described in more detail below) and hence biophysical feasibility. There are many potential receptors relevant to the LVRRS, and not all could be reasonably addressed within the current time frame for delivery of the LVRRS by June 2020.

For this reason, the LVRRS has been designed to identify receptors of most value and significance for initial assessment, and of these, only those receptors with reasonable potential to be impacted by rehabilitation (as informed by the technical studies) are subject to detailed impact assessment.

Valued regional receptors are features of the region's natural and built environment, natural resources and heritage that are considered important, as determined through consultation with stakeholders and the community, in assessing the potential cumulative effects of mine rehabilitation.

The objective of the receptor analysis is to define and describe the characteristics of receptors within the LVRRS study area and to identify those receptors considered to be recognised or valued. This involves:

- Nominating criteria for identifying recognised regional receptors. 
- Applying the criteria to develop a comprehensive spatially-enabled database of recognised regional receptors.

- Establishing an inventory with baseline information on receptor type, location, ownership and current level of protection.

Metrics and thresholds for quantitative impact assessment are being defined for priority receptors, informed by existing published information and stakeholder consultation. Receptor metrics are the means by which impacts on receptors can be measured (e.g. changes inflow within a particular stretch of a river) and thresholds are the acceptable limits for each metric.

\subsubsection{Geotechnical metrics, thresholds and current status}

In considering potential mine rehabilitation impacts on receptors from ground movement effects related to pit lake landforms, an understanding of each recognised receptor's tolerance (limits of acceptable change or risk) to ground movement is needed.

There is a variable level of documentation of the ground movement tolerance levels of receptors located in the Latrobe Valley region. For some recognised regional receptors, tolerance levels or the capacity to endure subjection to ground movement, are well defined (e.g. train lines) and in other instances there is no clear definition of tolerability levels. General tolerability levels may also be defined within guidelines pertaining to the type of receptor.

The objective of this task is to identify the geotechnical related measures or metrics used to quantify ground movement in relation to physical assets, and to determine the current status of those metrics.

\subsubsection{Water and environmental metrics, thresholds and current status}

This task aims to define the metrics (measures) and corresponding thresholds to be used to assess the degree of impact or effect of the rehabilitation scenarios on water-related receptors, and the available information on the current status and trend of water-related receptors. This foundational work provides a reference for assessing the likely impacts and the degree to which the status of a receptor could change under various rehabilitation scenarios.

\subsection{Geotechnical studies}

The geotechnical studies span Stages 2 to 4 of the project.

\subsubsection{Collation and compilation of existing geotechnical data and methods}

This study supports the assessment of regional cumulative impacts of mine rehabilitation by compiling disparate geotechnical information held by stakeholders into a single dataset of existing regional knowledge.

The objectives of this task are to collate and compile existing baseline geotechnical data and analysis methods for assessment of regional impacts of potential future ground movement within the LVRRS study area. Broadly, the task is to:

- Define the principal geo-mechanical processes relevant to ground movement.

- Outline geological, hydrogeological and geotechnical information used in assessing regional ground movement.

- Determine whether geotechnical data and analysis methods commonly used are fit for the purpose of preparing the LVRRS. 


\subsubsection{Geotechnical effects preliminary assessment}

This task draws together outcomes of studies related to regional recognised receptors, geotechnical baseline information and proposed mine pit lake rehabilitation scenarios to provide a preliminary assessment of mine rehabilitation geotechnical effects on recognised receptors.

The objective of this task is to undertake a preliminary assessment of the regional impacts of rehabilitation scenarios at each of the LVRRS temporal time scales.

Mine rehabilitation effects on recognised receptors requires consideration of a number of factors:

- Mining has to date induced land movement at the regional and inter-mine scale.

- The current extent and magnitude of impact needs to be defined to identify recognised receptors that may have experienced impacts from land movement to date.

- Mine rehabilitation based on pit lakes has potential to continue/alter/mitigate land movement effects.

- The potential nature and extent of future land movement impact needs to be assessed to identify recognised receptors that may be at risk from mine rehabilitation.

\subsubsection{Geotechnical effects quantitative assessment}

The objective of this task is to quantitatively assess the potential for regional rehabilitation scenarios (specifically pit lake filling) to drive/alter/re-initiate ground movement that would affect recognised regional receptors in the short, medium and long-term. A clear understanding of likely adverse impacts associated with implementing each regional rehabilitation scenario concerning subsidence/rebound and ground movement effects is required.

Output from this task provides a detailed geotechnical evaluation of the type, extent and consequence of ground movements that may pose risks to recognised regional receptors.

\subsubsection{Regional geotechnical monitoring plan}

The objective of this task is to review the potential land movement effects from rehabilitation and identify a geotechnical monitoring regime for assessing impacts to recognised receptors that complements existing monitoring. The plan identifies key monitoring requirements in conjunction with existing geotechnical monitoring.

\subsection{Water and environmental studies}

A key focus for the LVRRS is the potential implications and impacts of pit lake remediation on water resources and water-dependent environmental values. The questions that the LVRRS is attempting to answer include:

- What is the likely demand for water to fill and maintain the pit lakes over the short, medium and long-term, and is there sufficient water to meet this demand?

- What alternate water sources might be available for filling pit lakes?

- How long will it take to fill each mine pit?

- What is the current and future regional water balance, and what would be the effect of one or more pit lakes?

- What is the likely pit lake water quality for terminal and through-flowing pit lakes, and what could be the downstream and groundwater impacts on water users and the environment?

- How might alteration of the existing water regime impact water-dependent environmental values? 
- How might climate change and climate variability affect the viability of pit lakes and the health of water-dependent environmental values over the medium and long-term?

In order to answer these questions, the LVRRS is modelling surface water, groundwater and pit lakes under a range of rehabilitation scenarios and water source options and comparing the results with environmental and water demand thresholds on a regional cumulative basis. There are a number of steps that are needed to complete this study, from baselining and scoping, through to additional investigation, model development, numerical modelling and finally assessment and reporting. These steps are summarised in Figure 2 and described below.

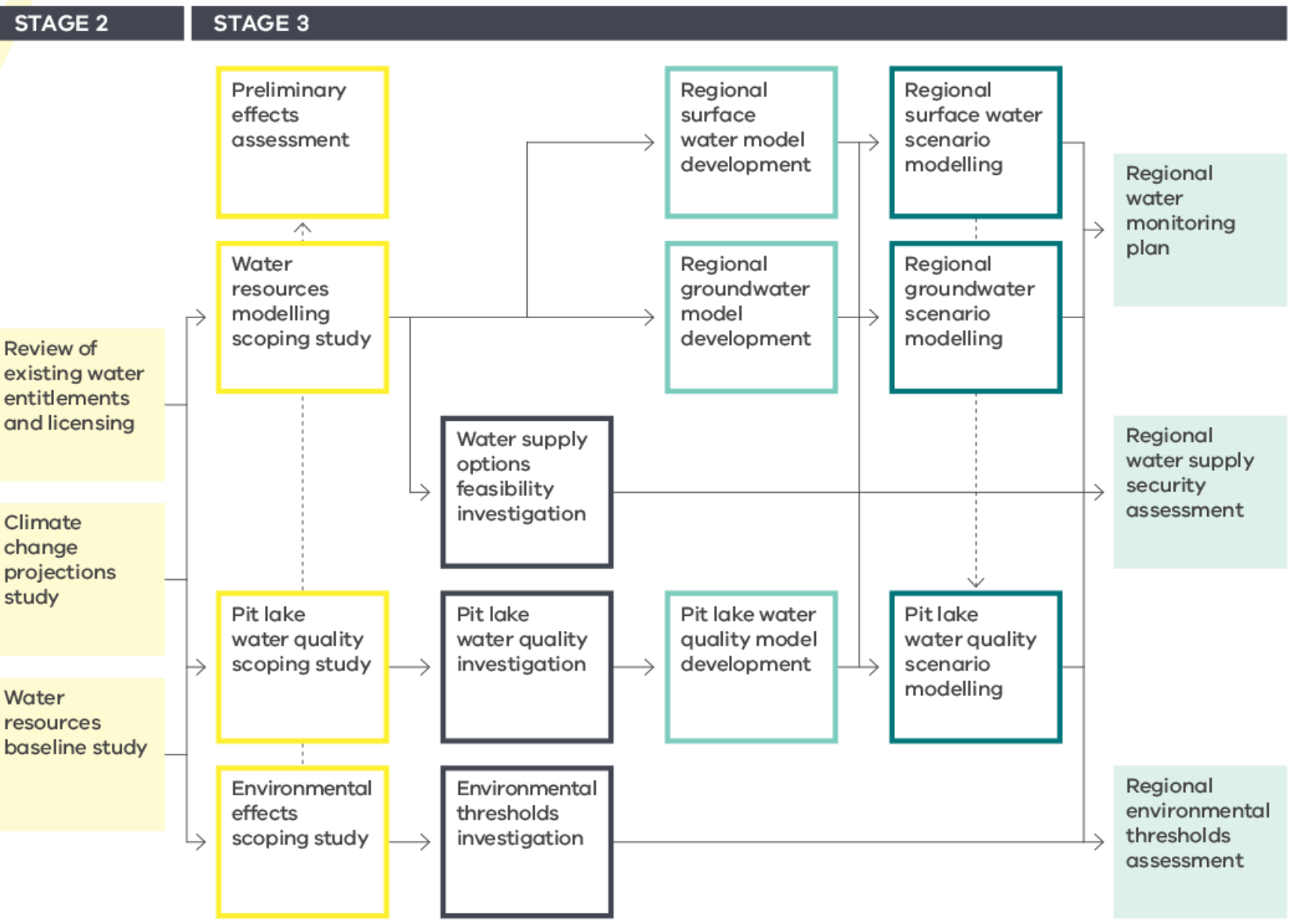

STUDY PHASE

BASELINE

SCOPING

INVESTIGATION

MODELDEVELOPMENT

MODELLING

ASSESSMENT

Figure 2 LVRRS water and environmental studies forming the regional water study (Stage 2/3)

\subsubsection{Baseline}

The baseline phase corresponds to Stage 2 (Existing Conditions Review) of the Implementation Plan. This phase captures the current state and what is known about existing and future factors relating to water and the environment in the context of the LVRRS.

\subsubsection{Review of existing water entitlements and licensing}

This task is a review of the legislative and regulatory status of existing water entitlements, licensing and allocations relevant to the closure and rehabilitation of the Latrobe Valley coal mines and associated power stations. 
This review provides information on the availability of various existing water sources for rehabilitation as key inputs into subsequent water resource modelling studies.

\subsubsection{Climate change projections study}

The viability of pit lakes over the medium to long-term, both during the rehabilitation (filling) period and into the future, needs to take account of potential changes to water availability as a result of climate change and long-term climate variability (such as periods of prolonged drought). However, understanding and predicting climate over such timeframes is highly uncertain, and different climate models can predict markedly different outcomes.

The climate change projections study provides a basis for how climate change can be integrated in the LVRRS studies, and how uncertainty and sensitivity to climate can be captured in assessing the impacts and implications of various rehabilitation scenarios.

\subsubsection{Water resources baseline study}

A rigorous understanding of the water resources in the Latrobe Valley and how these are allocated and used by people and the environment is fundamental to the LVRRS.

The water resources baseline study compiles existing knowledge and data sources on water allocation and use, water availability, water quality and aquatic ecosystems, for both surface water and groundwater, to inform subsequent water resource modelling and environmental studies.

\subsubsection{Scoping}

In order to model and assess pit lakes and their impacts, it is necessary to understand the factors, processes and sensitivities applicable to these water systems. The scoping studies develop an agreed, expert- and stakeholder-informed approach to how each component of the system should be studied, modelled and assessed. The scoping phase represents pre-work for Stage 3 (Modelling and Analysis) of the Implementation Plan.

\subsubsection{Investigation}

The LVRRS uses existing information and data to the extent feasible to complete the technical studies. However, specific data gaps critical to completing key studies are addressed through supplementary investigations as part of Stage 3 of the Implementation Plan.

\subsubsection{Water supply options feasibility investigation}

A comprehensive range of existing and alternative potential water sources for filling the mine pits is canvassed as part of the water resource modelling scoping study. The water supply options feasibility investigation explores these water sources in more detail to gain a clearer understanding of their comparative feasibility in terms of logistics, costs, infrastructure requirements, timing, availability, regulatory and licensing requirements, water quality and potential supply volumes.

\subsubsection{Environmental thresholds investigation}

This investigation addresses critical data gaps identified through the environmental effects scoping study, such as the flow and water quality limits of representative sensitive components of the Gippsland Lakes system.

\subsubsection{Pit lake water quality investigation}

This investigation addresses critical data gaps identified through the pit lake water quality scoping study, such as any water, overburden or coal sampling and analysis that may be needed to improve the prediction of pit lake water quality. 


\subsubsection{Model development}

The conceptual models and data inputs established through the scoping studies and supplementary investigations inform selected models, which are developed from scratch or adapted and refined from existing models for the purpose of modelling the specific rehabilitation scenarios to be considered in the LVRRS.

\subsubsection{Regional surface water model development}

This study adapts and refines the surface water model selected through the water resources modelling scoping study for use in modelling of specific rehabilitation scenarios.

\subsubsection{Regional groundwater model development}

This study adapts and refines the groundwater models selected through the water resources modelling scoping study for use in modelling of specific rehabilitation scenarios.

\subsubsection{Pit lake water quality model development}

This study develops a uniform pit lake model to be used for all three mines as the basis for modelling of specific rehabilitation scenarios.

\subsubsection{Modelling}

The calibrated models are used to predict the effects of rehabilitation under the various LVRRS scenarios, and to explore options for water supply and connectivity.

\subsubsection{Assessment}

The final assessment phase of the regional water study uses the results of modelling and analysis to assess the impacts of rehabilitation on regional water supply security and the environment, and to outline a water monitoring plan to track key performance outcomes focusing on gaps in existing monitoring networks/capabilities and options to address those gaps.

\subsection{Land Use Planning Studies}

The Land Use Planning Studies are conducted in parallel with the other studies comprising the LVRRS and form a key input into the feasibility assessment and final strategy.

The key objective of the LVRRS land use studies is to ensure that the final safe, stable and sustainable rehabilitated sites are able to support productive and high-quality land uses, which benefit the communities of the Latrobe Valley, Gippsland and Victoria. The studies form a comprehensive land use strategy for the mine pits and surrounding areas, which identify the potential land uses that may occur due to the pit lake landform scenario at an inter-mine, catchment and regional scale.

As stated, it qualitatively analyses the potential social and economic effects associated with identified land uses as well as potential regional measures that could be taken to avoid, minimise or enhance economic and social effects (e.g. changes in land use planning controls).

Working with the Latrobe City Council and other stakeholders, this study develops a regional understanding of potential social and economic impacts of changes in land uses associated with regional rehabilitation scenarios and their respective levels of community acceptability. Workshops and creative place-making sessions canvas broad options and opinions in the context of the findings of the LVRRS and government objectives within the Valley. The studies consider how the rehabilitation of the three mine pits and surrounding areas may impact sites of heritage value, areas of environmental and state resource significance, physical infrastructure and current and existing urban growth patterns, including residential, industry and rural land uses at different spatial scales. The resulting land use strategy identifies, evaluates 
and proposes productive land use changes to assist the Latrobe Valley economy in its transition and diversification, while adding benefits, which are identified by the community.

The activities informing the land use project are aligned with the staging of the LVRRS project plan as described below and shown schematically in Figure 3.

\begin{tabular}{|l|l|l|l}
\hline STAGE 2 & STAGE 3 & STAGE 4 & BEYOND
\end{tabular}

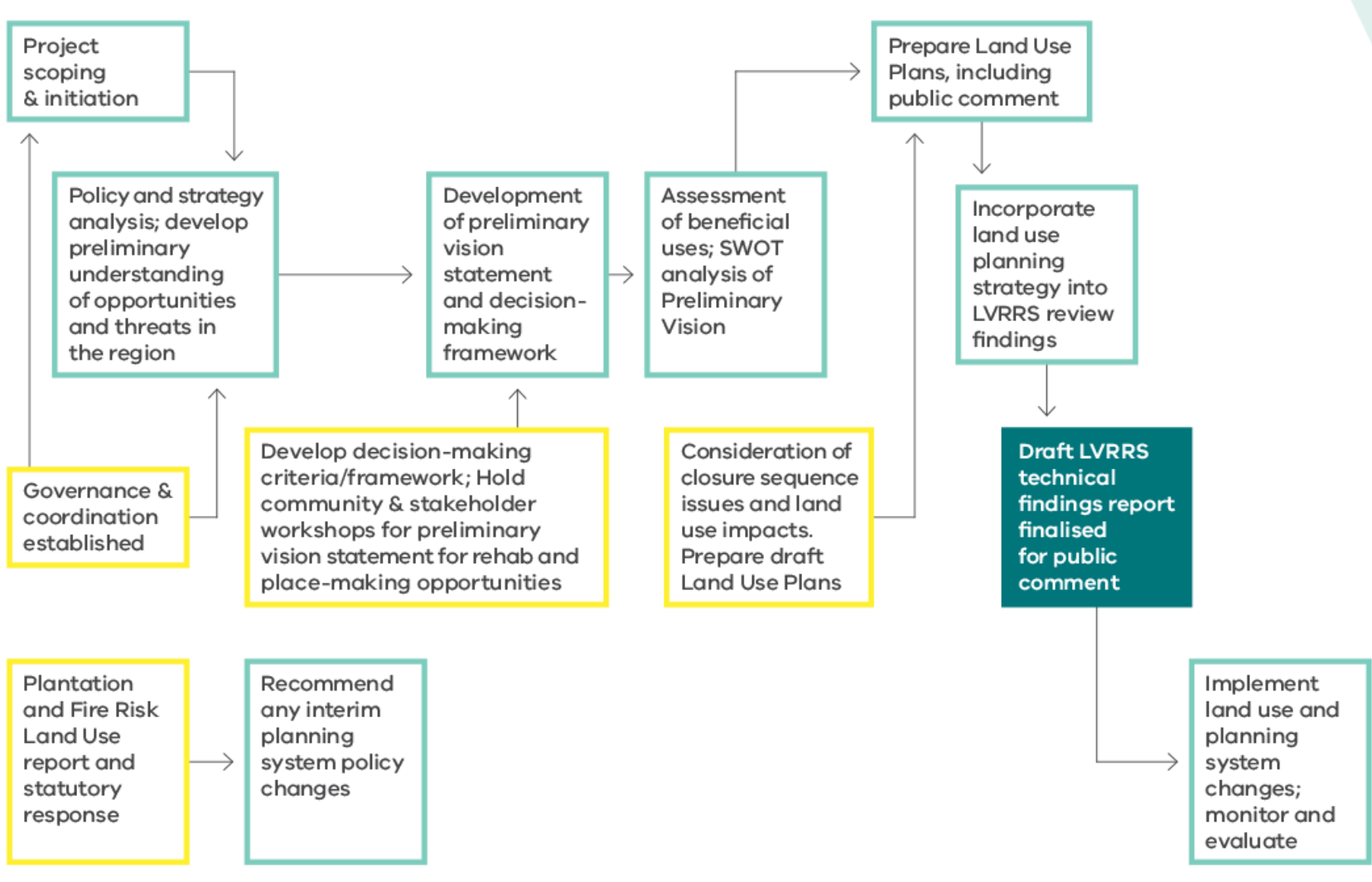

KEY

MAJOR INITIATIVES \& ACTIONS SUB-PROJECTS

Figure 3 Land use studies

\subsubsection{Stage 2}

Activities toward the land use strategy in Stage 2 are focused on project planning, ensuring that the project is aligned with the LVRRS and its timelines, findings and engagement activities, and also with wider government initiatives to transition the local economy.

The output of this stage is a suite of project management documents and an approved path for decisionmaking in association with land uses and relevant state policies. The Land Use Planning Studies consider aspects such as urban growth, and long-term industry and land use requirements, existing adjoining land uses and opportunities and constraints associated with pit lakes, and engagement processes to identify principles and a preferred preliminary vision for the Latrobe Valley mine sub-region.

\subsubsection{Stage 3}

Visioning and place-making exercises are reviewed at the completion of LVRRS stages as appropriate. This ensures an iterative response to the findings of the feasibility of pit lake options across all mine sites, noting inter-mine and regional land use implications. Liaison with the Latrobe Valley and broader Victorian communities, mine operators and other government departments occurs through this stage. 


\subsubsection{Stage 4}

This stage involves responding to the vision and principles established in Stage 3 and integrating these objectives and findings into the final LVRRS report. Critical decision-making is by the Minister for Planning as the ultimate decision maker regarding land use planning in the Latrobe Valley in accordance with the Minister's responsibilities under the Planning and Environment Act 1987 (Government of Victoria 1987). Following this, the LVRRS is formally adopted and any identified planning system changes implemented.

\subsection{Cumulative impact assessment}

The cumulative impact assessment integrates the Stage 3 technical studies as the main focus of Stage 4 of the LVRRS.

As a regional rehabilitation strategy, the LVRRS is principally focused on the combined effects of all three rehabilitated coal mines. Therefore, while it is necessary to model and assess each mine separately to understand the requirements, constraints and consequences of different rehabilitation scenarios, it is equally necessary to assess the impacts and implications of various combinations of individual mine rehabilitation strategies with regard to the cumulative effects on the region including the downstream environment.

The LVRRS has adopted a standard cumulative impact assessment approach to evaluating such cumulative effects. The Sustainable Minerals Institute and Minerals Council of Australia have developed by the World Bank and in Australia guidelines and standards for cumulative impact assessments.

The core principles for the cumulative impact assessment for the LVRRS are outlined below.

\subsubsection{Source-Pathway-Receptor model}

Impacts are defined as the effect of one action or process on some other object, action, process or other thing of value. The origin of the impact is referred to as the 'source', and the impacted 'thing' is referred to as the 'receptor'. In addition, for there to be an impact, there needs to be a causal link between the source and receptor, called the 'pathway'.

For example, earthworks could be a 'source' of sediment, a wetland could be a 'receptor', and downstream transport of sediment by erosion and deposition in the wetland could be a 'pathway' by which the earthworks could impact the wetland.

\subsubsection{Regional rehabilitation scenarios (source)}

The sources in the LVRRS cumulative impact assessment are the three mines, which have different rehabilitation modes, final landforms and rehabilitation timings under different regional rehabilitation 'scenarios'. For the purposes of cumulative impact assessment, the three mines are regarded collectively as a single composite source under each scenario. The LVRRS considers a manageable set of scenarios that test the main representative final landforms that could be practically achievable.

\subsubsection{Recognised regional receptors (receptors)}

There are many potential receptors relevant to the LVRRS, and not all can be reasonably addressed within the time frame for delivery of the LVRRS. For this reason, the LVRRS has been designed to identify receptors of most value and significance for initial assessment, and of these, only those receptors with reasonable potential to be materially impacted by rehabilitation (a clear pathway) are subject to detailed impact assessment.

Recognised regional receptors are features of the region's natural and built environment, natural resources and heritage that are considered to be important, through consultation with stakeholders and the community, in assessing the potential cumulative effects of mine rehabilitation. 
Appropriate receptor metrics and thresholds are defined and informed by existing published information and stakeholder consultation. Receptor metrics are the means by which impacts on receptors can be measured (e.g. changes inflow within a particular stretch of a river) and thresholds are the acceptable limits for each metric.

\subsubsection{Pathways}

The impact pathways are many and varied, and are explored through the LVRRS technical studies. The pathway determines the likelihood of event occurrence, which is considered in combination the consequence of an event occurring (i.e. severity of impact) to gauge the materiality of any given receptor for the purposes of the LVRRS.

\subsubsection{Exogenous effects}

The LVRRS cumulative impact assessment considers, to the extent practical given present knowledge, the effect of processes and plans beyond the scope of activities that could be controlled by the mine operators, such as climate change and long-term climate variability, and changes to regional land use including new economic activity.

\subsubsection{Quantitative versus Qualitative Impacts}

For each regional rehabilitation scenario, the potential cumulative impacts on recognised regional receptors are quantified where possible. Quantification of impacts involves estimating the potential condition of receptors under different regional rehabilitation scenarios over short, medium and long terms. The potential condition of receptors is compared with specified desired outcomes/thresholds for the acceptable condition of the receptor.

In some instances, there is a lack of agreed or valid quantitative information upon which to base assessments, or where such information may be difficult to acquire within the time frame available for the preparation of the LVRRS. If a recognised regional receptor is deemed to be of high importance and the LVRRS project concludes there is significant uncertainty regarding the extent of the effect on the receptor, the LVRRS may outline future actions (post June 2020) to improve the understanding of the potential effects of the regional rehabilitation scenarios.

\subsection{Biophysical feasibility assessment}

The final technical output of the LVRRS is a statement of biophysical feasibility of a range of regional rehabilitation scenarios. This involves assessment of the biophysical feasibility of multiple pit lake landforms over the short, medium and long-term based on the regional geotechnical and water studies, the cumulative effects of the three coal mines on recognised regional receptors, and the land use studies.

The key focus for the LVRRS project is the potential cumulative impacts on regional water resources and land stability associated with the proposed pit lake landforms.

Water resource aspects include: likely demand for water to fill and maintain the pit lakes and the regional capacity to provide sufficient water (surface water and groundwater) in the context of climate change, the impacts of altering the existing water regime on regional water quality and flow, the effect on groundwater levels and associated impacts, and impacts on the Latrobe River, Lake Wellington, Gippsland Lakes and associated water-dependent ecosystems and cultural values.

Land stability aspects include the current and projected future state of features in proximity to the proposed pit lakes, their tolerance to ground movement, the potential likelihood and consequences of ground movement and what controls are required to avoid, mitigate and/or offset regional ground movement risk. 
Biophysical feasibility statements for water, land stability and land use are key inputs to the final LVRRS report, and provide government and its agencies, stakeholders and the community with a clear understanding of the specific issues and considerations for each rehabilitation scenario.

The goal of the feasibility statements is to clearly define the regional rehabilitation scenario(s) and the recognised regional receptors for which:

- Cumulative effects are acceptable (regional rehabilitation scenario(s) which are feasible).

- Cumulative effects are not acceptable unless mitigated or offset, with some description of the mitigation measures or offsets that may be able to be adopted.

- Cumulative effects are unacceptable and cannot be mitigated or offset.

\subsection{Stakeholder and community engagement}

Open and transparent engagement with community and stakeholders is critical to the development of the LVRRS. A stakeholder and community engagement strategy (DJPR 2018) guides the engagement program that underpins the preparation of the LVRRS.

\section{Outcome for the community}

The aim of the LVRRS is to set a safe, stable and sustainable landform for the Latrobe Valley coal mine voids and surrounding areas, providing assurance to the community. It will achieve this by exploring the effects and implications of a range of regional rehabilitation scenarios, providing government and the community with the information needed to make an informed decision regarding the future direction of mine rehabilitation and supported land uses.

\section{Acknowledgement}

The authors thank the following for their tireless support:

- The LVRRS project team in the planning and delivery of the LVRRS, including current and former team members across DJPR, DELWP, Jacobs Group, MiningOne, Cameron Strategies, Sherwood Geotechnical and Research Services, GHD, Alluvium, SMEC, R4RISK, RGS Environmental, Earth Systems, Mine Lakes Consulting, Environmental Geochemistry International, O'Kane Consultants, Water Technologies, Jennifer Hale and Associates, Crossbow Consulting Services, SalsaDigital, CSIRO, University of Melbourne and the University of Queensland.

- The Latrobe Valley Mine Rehabilitation Commissioner and his staff for their advice, reviews and assistance in community engagement.

- Technical peer reviewers including experts from Federation University, CSIRO, National Centre for Groundwater Research and Training, Adaptive Strategies, Pitt and Sherry, CDM Smith, and Galvin and Associates.

- Past and present members of the Latrobe Valley Mine Rehabilitation Advisory Committee for their valuable inputs and advice.

- Key stakeholders including Engie Hazelwood, EnergyAustralia Yallourn, AGL Loy Yang, Latrobe City Council, Gippsland Water, Southern Rural Water, West Gippsland Catchment Management Authority, and the Gunaikurnai Land and Waters Aboriginal Corporation for their valuable inputs and advice. 


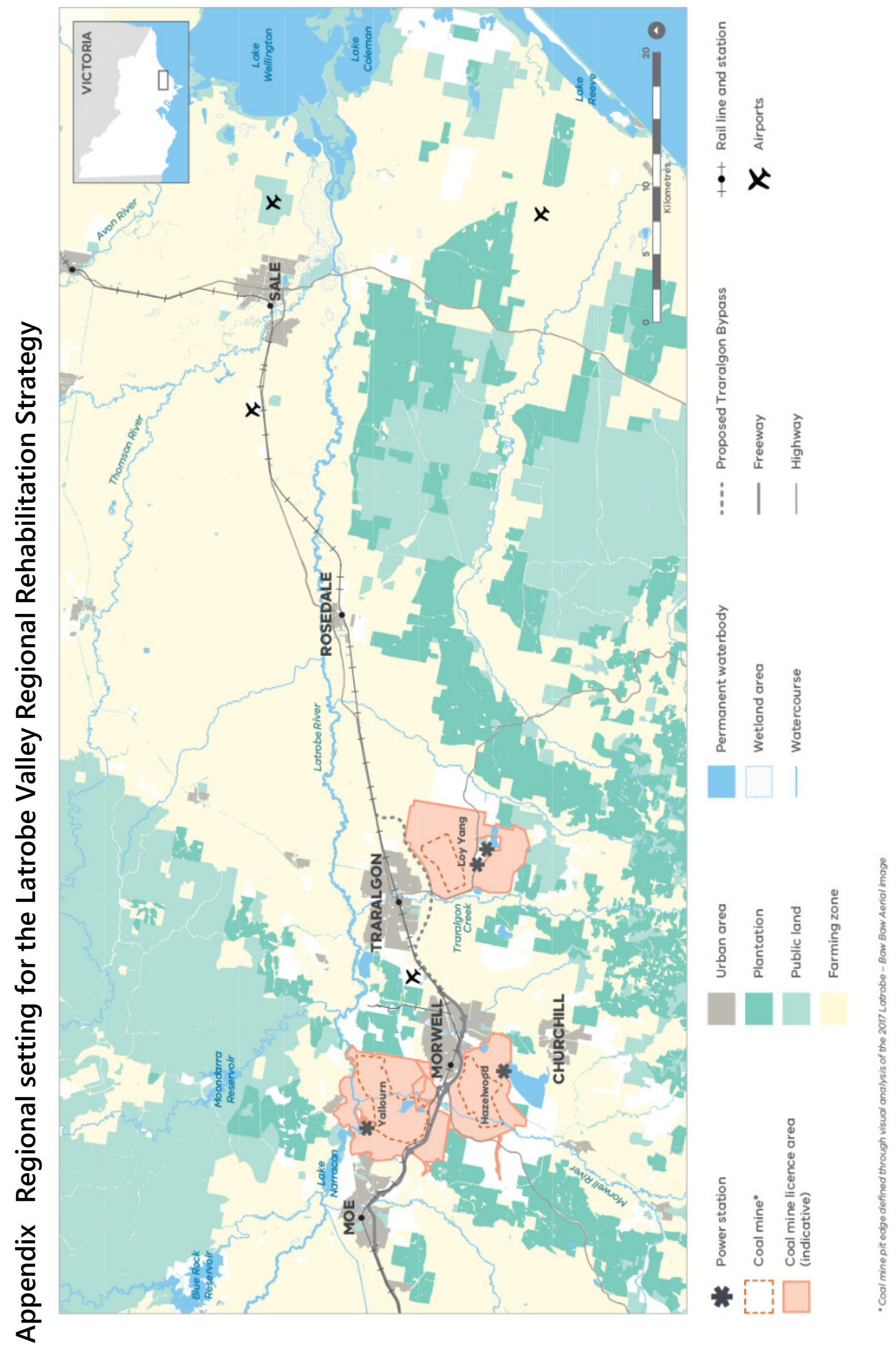




\section{References}

Department of Jobs, Precincts and Regions 2018, Latrobe Valley Regional Rehabilitation Strategy, Earth Resources, State Government of Victoria, Melbourne, viewed 8 April 2019, http://earthresources.vic.gov.au/earthresources/hazelwood/hazelwood-mine-fire-inquiry-implementation-plan/the-latrobe-valley-regional-rehabilitation-strategy Government of Victoria 1987, Planning and Environment Act 1987, Australia.

Hazelwood Mine Fire Board of Inquiry 2016, Hazelwood Mine Fire Inquiry Report 2015/2016 Volume IV-Mine Rehabilitation, Melbourne.

State of Victoria 2016, Hazelwood Mine Fire Inquiry: Victorian Government Implementation Plan, Melbourne. 
